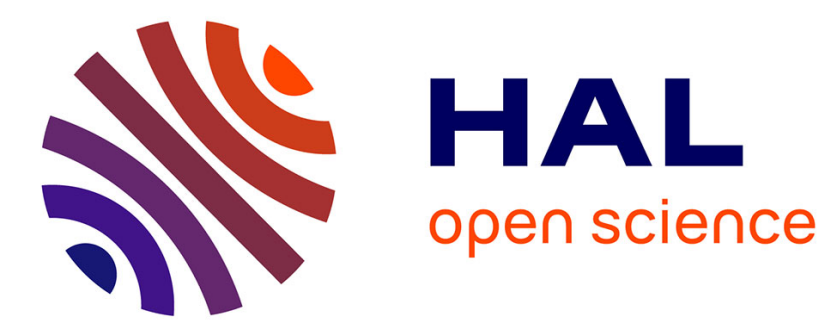

\title{
A combinatorial optimisation approach to energy management strategy for a hybrid fuel cell vehicle Stéphane Caux, Yacine Gaoua, Pierre Lopez
}

\section{To cite this version:}

Stéphane Caux, Yacine Gaoua, Pierre Lopez. A combinatorial optimisation approach to energy management strategy for a hybrid fuel cell vehicle. Energy, 2017, 133, pp.219-230. 10.1016/j.energy.2017.05.109 . hal-01531987

\section{HAL Id: hal-01531987 \\ https://hal.science/hal-01531987}

Submitted on 2 Jun 2017

HAL is a multi-disciplinary open access archive for the deposit and dissemination of scientific research documents, whether they are published or not. The documents may come from teaching and research institutions in France or abroad, or from public or private research centers.
L'archive ouverte pluridisciplinaire HAL, est destinée au dépôt et à la diffusion de documents scientifiques de niveau recherche, publiés ou non, émanant des établissements d'enseignement et de recherche français ou étrangers, des laboratoires publics ou privés. 


\title{
A Combinatorial Optimisation Approach to Energy Management Strategy for a Hybrid Fuel Cell Vehicle
}

\author{
Stéphane Caux \\ LAPLACE, Université de Toulouse, CNRS, INPT, UPS, Toulouse, France \\ Yacine Gaoua \\ LAAS-CNRS, Université de Toulouse, CNRS, Toulouse, France \\ LAPLACE, Université de Toulouse, CNRS, INPT, UPS, Toulouse, France \\ Pierre Lopez \\ LAAS-CNRS, Université de Toulouse, CNRS, Toulouse, France
}

\begin{abstract}
Hybrid Electric Vehicles are becoming more and more prevalent for economic and environmental reasons. Many studies have been conducted in order to improve Hybrid Electric Vehicle performance by increasing their autonomy while respecting the power demand of the electric motor and various constraints. Focusing on the Hybrid Electric Vehicle energy management problem, different approaches and strategies already exist based on non-linear modelling, selection of adequate architecture and source design or the expertise of the manufacturer in the domain. In this paper, a new combinatorial approach is presented to optimally manage offline Hybrid Electric Vehicle energy distribution, composed of two energy sources: a fuel cell as a main source and a super-capacitor for energy storage. New mathematical mod-
\end{abstract}

Email addresses: caux@laplace.univ-tlse.fr (Stéphane Caux), y.gaoua@yahoo.com (Yacine Gaoua), pierre.lopez@laas.fr (Pierre Lopez) 
elling has been developed that reflects the functioning of the Hybrid Electric Vehicle energy chain, using an exact method to provide an optimal solution that corresponds to hydrogen consumption. Simulations were performed on different realistic mission profiles that showed a significant gain in solution quality and computation time compared with other approaches presented in the literature. Since the quality of solutions depends on the reliability of input data, including disruptions, a robustness study also is carried out.

Keywords: Fuel Cell Vehicle, Energy Management, Global Optimisation, Combinatorial Approach, Integer Linear Programming, Robustness.

\section{Introduction}

On Earth, more than one billion cars circulate today, and manufacturers produce more than 80 million new vehicles every year [1], in addition to other means of transport, nearly all propelled by an Internal Combustion

5 Engine (ICE) with conventional energy (gas and oil). A huge amount of carbon dioxide particles is released daily in the atmosphere, that is harmful to human health and to the environment. The public, better informed of climate change risks by extensive literature, and the scientific community now are organised to put pressure on political and economic decision-makers to take appropriate measures to counteract this threat and promote energy transition. Car manufacturers contributing to this policy, as well, invest in research and development of new vehicle prototypes with hybrid or full electrical energy traction [2].

Even though the first Hybrid Electric Vehicle (HEV) was conceived at the end of 19th century, the low autonomy and the important mass of elec- 
tric vehicles encouraged the industry to develop and use ICE, since oil was available, affordable and the number of vehicles was low. Over time and because of rising oil prices and abnormal rate of $\mathrm{CO}_{2}$ emissions in the air, car manufacturers and researchers conducted a lot of research in order to commercialise a new generation of HEVs equipped with renewable energy sources with a better performance.

The energy management field is very large, also in transportation applications. Actually, many research works deal with solving to optimality energy and power delivered by several decentralised sources, most of them using renewable energy sources. Hydrogen and Fuel Cell are promising in such mobile systems. The optimal problem is more complex when the design-case and the use-case are mixed.

In [3], it can be noticed it is more convenient to separate two problems depending on the time horizon. For a long term, energy management can be driven with criteria depending on prediction, cost of investment and infrastructure and sizing optimization steps. A real-time energy management is requested for an optimal power split on-board subject to power and energy constraints using given sizing elements and power train architecture; all studies for plug-in HEV or linking HEV to the grid are specific too.

In [4], it can be seen the strategy will be different and also the optimisation criterion can be different. In HEV traction case, the power demand has to be delivered (no scheduling and no peaks cancelling policy are possible). A global optimisation is thus possible knowing the power flow characteristics and the entire mission profile. A global optimum is reached subject to energy 40 minimization all over the known trip. 
In this paper, a particular hybrid structure of an electric vehicle with two sources is considered: Fuel Cell (FC) as a main source of electrical energy used for the propulsion of the vehicle (called a powertrain or traction chain), and a pack of super-capacitors for energy storage used to support the FC during traction phases. The goal is to improve vehicle autonomy with the knowledge of the mission profile to achieve. Nevertheless, offline smart energy management is crucial if the demands of the electrical engine are to be met while respecting different HEV constraints related to system function, safety conditions, and sources design.

Different approaches were studied in previous works, in order to manage energy distribution for the same type of traction chain and increase its autonomy by minimising fuel consumption by the main source. Among these approaches, the most cited in the literature is undoubtedly Dynamic Programming, used offline when the mission profile is known [5]. This method, based on Bellman's principle after the discretisation of the energy space of the storage system [6], reveals some weaknesses related to the choice of the discretisation step-size that significantly affects computation time and decision quality. Another method frequently cited in this problematic is an Optimal Control approach [7] based on Pontryagin's minimum principle and the calculation of derivatives of the Hamiltonian function [8] or the reporting of all source consumptions in an equivalent space where optimal control is conducted (equivalent consumption management strategy [9]). This method induces polynomial approximation, which generates some errors and does not take into account some saturation constraints due to the limitation in sources design. Moreover, parameter setting to satisfy the state of energy 
constraints is somehow tricky.

Recently, much work has been carried out, mainly to accurately solve the global optimisation problem offline when the mission is known (based on multi-level [3], simulated annealing [4], quasi-Newton method [6]) or by using artificial intelligence approaches (e.g., Particle Swarm Optimisation [10]). Other methods are preferred in the literature with real-time on-line implementation objectives: an on-line optimal control approach [11] with an adaptive principle (equivalent consumption minimisation strategy - ECMS [12]) or heuristics and rule-based approaches (Fuzzy Logic [13] and type-II 75 optimized Fuzzy Logic [14] possibly in combination with a genetic algorithm [15] or adding an adaptive mechanism [16]), in order to minimise hydrogen consumption by the fuel cell system. Control strategies based on load following also have been experimented in [17]. The solutions obtained by these approaches are suboptimal due to their non-linear formulation of the problem or the setting of some parameters generally involving important computation times.

In the work presented in this paper, the above state-of-the-art approaches are exploited with the objective of comparing them with the new propositions. Therefore, a new approach is proposed to address the best power set points for the HEV system in order to manage energy distribution and minimise hydrogen consumption with a reduced computation time. It consists of proposing a new linear modelling, which is then solved to optimality by using Integer Linear Programming. To speed up the optimisation process, cutting planes are added to the original formulation to reduce the search space. The 90 problem is formulated in this paper as a combinatorial problem using set 
points corresponding to data representing the source behaviours subject to constraints of power and energy limits and consumption minimisation. This approach is new and very different from classical studies because there is no need of derivative functions nor polynomial approximations. (Mixed-)Integer Linear Programming can be used to solve approximate linearized problem, however the proposed formulation overcomes some drawbacks, provides the optimum and is less time consuming to be implemented in real time on-board. The optimal solution is the series of optimal set points to follow the mission with the minimum consumption cost defined. To measure the sensitivity of the problem against input data disruptions, a robustness study is performed to achieve a worst-case solution to be valid regardless of the scenario. Simulations based on several realistic mission profiles illustrate the improvement using the novel modelling.

The paper is organised as follows: First, Section 2 presents the different sources and components that constitute the HEV energy chain. Then Section 3 provides a survey of the most used approaches in the literature that address this problem. This section provides basis results from which it will be possible to draw comparisons with the new proposed approach. Section 4 is devoted to the proposed contribution using new mathematical modelling and approaches in order to reach better power references to optimally manage HEV energy distribution. Results of simulations on realistic mission profiles to illustrate the performance are presented in Section 5, followed by a robustness study in Section 6. 


\section{Hybrid vehicle structure}

115 series hybrid configuration, which means that two contributions are added onto an electrical node before feeding the electrical moto-propulsion group, as shown in Figure 1.

\section{INSERT FIGURE 1 ABOUT HERE}

A Fuel Cell Stack (FCS) represents the main source producing energy via the chemical reaction of hydrogen and oxygen. It is characterised by its high efficiency, which exceeds $40 \%$ (mainly limited to compressor and ancillary losses) [18], generating electrical energy with little fuel, unlike the performance of ICE, which varies between $25 \%$ and $30 \%$ [19]. It should be noted that the energy converted by FCS also emits water steam and heat, which can be used as a secondary need. This aspect of cogeneration potential is not treated in this paper.

The FCS efficiency curve shown in Figure 2 is based on experimental measurements. It is expressed under a fixed cathodic pressure and a fixed temperature and measurements establishing a unique polarisation curve. This quantity, denoted by $\eta_{f c s}$, corresponds to the entire stack, thus is computed using the static fuel cell core efficiency $\eta_{f c}$, which can be given by the manufacturer or by measurements [15], the efficiency of their ancillaries such as an air compressor ${ }^{1} \eta_{\text {compressor }}$, and the efficiency of the embedded in the

\footnotetext{
${ }^{1}$ Air compressor represents $80 \%$ of the energy consumed by all the FCS ancillaries (air compressor, temperature and humidification regulating pumps, converter, etc.).
} 

It yields:

$$
\eta_{f c s}=\eta_{f c} . \eta_{\text {compressor }} \cdot \eta_{c v s}
$$

\section{INSERT FIGURE 2 ABOUT HERE}

In this paper, the efficiency curve used shows that maximum FCS efficiency can reach $46 \%$ when the FCS provides around $24 k W$ [10].

140

The energy chain also includes a Storage Element (SE) composed of a pack of super-capacitors, which can support the FCS in the acceleration phases to obtain a better performance of the overall traction chain and can be recharged during vehicle braking phases (reversible element). The SE is characterised by its storage capacity $E_{n o m}$ and its power losses shown in Figure 2b, denoted by Loss $_{\text {se. }}$. SE power losses are computed using buck-boost converter losses $L_{0 s s_{c v s}}$ and power lost by the super-capacitors pack $R_{s c} I_{s c}^{2}$, where $I_{s c}$ corresponds to the current flowing through the super-capacitors pack, and $R_{s c}$ its equivalent resistor, which has a non-linear form (not the same in charge and discharge mode).

$$
\operatorname{Loss}_{s e}=\operatorname{Loss}_{c v s}+R_{s c} I_{s c}^{2}
$$

\section{Mathematical modelling}

The objective is to minimise hydrogen consumption used by the FCS throughout the mission, while satisfying system constraints. Many studies have been

\footnotetext{
${ }^{2}$ The converter is an electronic module delivering a current to maintain with intern control loops the bus voltage to its reference despite voltage variations of the FCS and the storage system. It is characterised by its high efficiency, ranging from $93 \%$ to $97 \%$.
} 
realised on non-linear modelling due to source characteristics (FCS efficiency and SE power losses), using the following modelling:

$$
\begin{array}{ll}
\min \sum_{t=1}^{T} P_{h}(t) \Delta t \equiv \min \sum_{t=1}^{T} \frac{P_{f c s}(t)}{\eta_{f c s}\left(P_{f c s}(t)\right)} \Delta t & \\
P_{f c s}(t)+P_{s e}(t) \geq P_{r e q}(t) & \forall t \in T \\
0 \leq P_{f c s}(t) \leq P_{f c s}^{\max } & \forall t \in T \\
P_{s e}^{\text {min }} \leq P_{s e}(t) \leq P_{s e}^{\max } & \forall t \in T \\
\operatorname{SoE}^{\text {min }} \leq \operatorname{SoE}(t) \leq \operatorname{SoE}^{\max } & \forall t \in T \\
\operatorname{SoE}(t)=\operatorname{SoE}(t-1)-P_{s}(t) \Delta t & \forall t \in T \\
P_{s}(t)=P_{s e}(t)+\operatorname{Loss}_{s e}\left(P_{s e}(t)\right) & \forall t \in T \\
\operatorname{SoE}(T)=\operatorname{SoE}(0) &
\end{array}
$$

$T$ is the time horizon (mission duration). The decision variables of the problem are: $P_{f c s}(t)$ the power provided by the FCS at time $t, P_{s e}(t)$ the power provided/recovered (positive/negative) by the SE at time $t$, and $S o E(t)$ the state of energy of the SE at time $t$. Input data of the problem are defined in Table 1. Consequently, the meaning of the mathematical model is as follows:

- (3): The objective function is to minimise the hydrogen consumption used by the FCS; it also can be written using the FCS efficiency and the power it provides. Hydrogen quantities $P_{h}$ are calculated using the operating points of the fuel cell efficiency (experimental data sheet), $P_{h}=P_{f c s} / \eta_{f c s}$. Then, the numerical equation of the objective function is achieved using a 15-degree polynomial taking into account the 
minimisation of the approximation errors.

- (4): Demand satisfaction of the powertrain when the vehicle is accelerating. The vehicle also recovers energy during braking phases via the transformation of the kinetic energy into electrical energy. However, recovering all braking energy can force the FCS to operate at poor efficiency: for example, when the mission profile begins with a descent and the driver brakes, this leads to the recovery of braking energy, or the saturation of the storage element, hence the importance of relaxation of $P_{f c s}(t)+P_{s e}(t)=P_{r e q}(t)$ using inequalities (4).

- (5) and (6): Power limits related to the design of the energy sources.

- (7): Storage capacity of the storage element. Generally, SE only can be used between $25 \%$ and $100 \%$ of its energy capacity.

- (8): State of energy computation using previous state of energy and recovered energy.

- (9): Energy losses of the storage element used to identify the real power $P_{s}(t)$ supplied/recovered by the storage element.

- (10): This constraint can be optionally added, meaning that the final state of energy of the storage system should be reloaded to its original level at the end of the mission. This constraint makes it possible to go from mission to mission without charging the storage system.

INSERT TABLE 1 ABOUT HERE 
To find the solution of the present problem, which corresponds to the consumption of hydrogen minimisation, mission profiles are proposed by the

190

\section{INSERT FIGURE 3 ABOUT HERE}

$$
\text { not only used to feed the study with actual trips but also highlight various }
$$
types of requests. Thus, figures show missions with partial part repetition, the presence or absence of stop phases, high dynamics (power variation / time) or low/high positive and/or negative magnitude. methods have been implemented for purposes of comparison: dynamic programming (DP), quasi-Newton method (QN), fuzzy logic (FL), etc., which make it possible to find a suboptimal solution as shown in Table 2 due to the polynomial approximation used in a QN approach or by the setting of parameters for a DP and FL approach (FL membership functions are optimally placed by offline supervision using genetic algorithms, while the form 
and number of chosen membership functions allow the problem to be defined accurately) [14].

\section{INSERT TABLE 2 ABOUT HERE}

The solution provided by a QN method is better in terms of solution quality and computation time, while respecting the constraint of the final state of energy. The DP approach is an exact method, but it depends on the choice of the step discretisation, which significantly impacts solution performance and computation time. It also should be noted that while the solution provided by an FL approach is good, the solution is calculated without taking into account the final state of energy constraint. This approach is efficient in a real-time strategy, but the setting of the fuzzy parameters in order to obtain a good solution requires offline optimisation, which itself requires long computation times.

225 The new combinatorial model will overcome these drawbacks because the combinatorial optimisation only selects one point among a set of points and returns the best sequence of points to follow to reach the minimum consumption.

Table 2 compares optimal consumptions obtained with the three "classical" methods on five mission profiles we compare here after to the new results obtained on the same missions.

In order to compare the performance of the solutions obtained with the new approach developed (see Section 5), the best solution provided by the QN method is used when the constraint of the final state of energy is taken into account, and FL is used for real-time computation when this constraint 
is deactivated. CPU times indicated depend on the processor, memory and programming environment used, but is interesting for relative comparison to discriminate among the different methods.

FL is a real-time optimisation approach (instantaneous optimisation, each time step) while the QN method is a global optimisation approach, which explains the consumption gap and the advantage of the QN method. To improve FL modelling, different fuzzy membership functions (more non-linear) can be used thereby increasing the time-setting procedure and badly impacting on-line implementation. Now that the results and drawbacks of such previous models and methods have been highlighted, the new combinatorial approach can be proposed. All derivative, approximation and sampling drawbacks are cancelled in this new combinatorial modelling driven by experimental data set-points to be optimally chosen.

\section{New combinatorial approach}

In this section, an original model for a HEV energy management is proposed. Modelling the problem as a linear program enables us to obtain an optimal solution using exact methods of operations research such as Branch-andBound or Branch-and-Cut procedures [20].

The principle of this new modelling is to work with the original data without using either SE energy space discretisation or polynomial approximations. For this purpose, a set of FCS operating points $K_{f c s}$ is defined from the input data sheet $\left(\left|K_{f c s}\right|=601\right)$ that allows plotting the FCS efficiency curve. Each point $i \in K_{f c s}$ is characterised by its efficiency $\eta_{f c s}(i)$ and the power it provides $P_{f c s}(i)$. In the non-linear modelling, the power 
In a combinatorial approach, the power losses function is decomposed into $|J-1|$ linear functions, and $J_{s e}$ denotes the set of linear functions, which forms the power losses function. Instead of polynomial approximation classically used in methods presented in Section 3 for the HEV field, this innovative modelling is data driven and provides a combinatorial formulation. There is no use of Hessian, derivative and so on. In this framework, the new decision variables of the combinatorial modelling are:

- $X_{i}(t) \in\{0,1\}$ the activation or not of the FCS operating point $i \in K_{f c s}$ at time $t$,

- $Y_{j}(t) \in\{0,1\}$ the activation or not of the linear function $j \in J_{s e}$ to calculate the power lost at time $t$,

- $P_{s e}(t)$ the power provided or recovered by the SE at time $t$,

- $S o E(t)$ the state of energy of the SE at time $t$,

- $\operatorname{Eloss}_{s e}(t)$ the power lost by the SE at time $t$.

Using the new decision variables, the objective function and some constraints defined in the previous modelling change and allow the definition of a novel formulation. The objective function that minimises hydrogen consumption becomes as follows:

$$
\min \sum_{t=1}^{T} \sum_{i=1}^{K_{f c s}} X_{i}(t) \frac{P_{f c s}(i)}{\eta_{f c s}(i)} \Delta t
$$


The above objective function is optimised under the following constraints. To satisfy the vehicle powertrain demand expressed in (12), constraint (13) is imposed, which means one FCS operating point is activated at each time:

$$
\begin{array}{ll}
P_{s e}(t)+\sum_{i=1}^{K_{f c s}} X_{i}(t) P_{f c s}(i) \geq P_{r e q}(t), & \forall t \in T, \forall i \in K_{f c s} \\
\sum_{i=1}^{K_{f c s}} X_{i}(t)=1, & \forall t \in T, \forall i \in K_{f c s}
\end{array}
$$

The second issue is how to linearise the SE power losses function. Knowing that the power losses curve (Figure 2b) is a piecewise linear convex function, it can be modelled as follows:

$$
\text { Eloss }_{s e}(t)=\alpha_{j} P_{\text {se }}(t)+\beta_{j}, \quad \forall P_{s e}(t) \in\left[\gamma_{j}, \gamma_{j}^{\prime}\right]
$$

with $\left(\alpha_{j}, \beta_{j}\right)$ the characteristics of line $j$ over interval $\left[\gamma_{j}, \gamma_{j}^{\prime}\right]$. To find the quantity of power losses corresponding to the power provided/recovered by the SE (Figure 4), a new formulation is proposed using the Max function (Eq. 15):

$$
\text { Eloss }_{s e}(t)=\max _{j=1}^{\left|J_{s e}\right|} \alpha_{j} P_{\text {se }}(t)+\beta_{j}, \quad \forall t \in T
$$

where $\left|J_{s e}\right|$ is the number of linear functions and $j \in J_{s e}$ its index.

\section{INSERT FIGURE 4 ABOUT HERE}

Knowing that Max function is also non-linear, it can be modelled as a system of linear equations using binary variables and a $b i g-M$ constant. It should be noted that $M$ should be a high value; a too-high value would not 
change the quality of the solution but it would uselessly increase computation time. So, $M$ must be chosen carefully, in terms of the scope of the data.

$$
\begin{array}{lrl}
\operatorname{Eloss}_{s e}(t) \leq \alpha_{j} P_{\text {se }}(t)+\beta_{j}+M\left(1-Y_{j}(t)\right), & \forall t \in T, \forall j \in J_{s e} \\
\operatorname{Eloss}_{s e}(t) \geq \alpha_{j} P_{s e}(t)+\beta_{j}, & \forall t \in T, \forall j \in J_{s e} \\
\sum_{j=1}^{J_{s e}} Y_{j}(t)=1, & \forall t \in T
\end{array}
$$

Constraint (18) means that one and only one linear equation $\alpha_{j} P_{s e}(t)+\beta_{j}$ is activated at each time $t$, amongst all the lines of the set $J_{s e}$.

Remaining constraints are let unchanged: i.e., energy recovery during brake phases, sources design (SE power limits and capacity), and SE energy level recovery at the end of the mission. Thus, the global novel linear model is: 


$$
\begin{aligned}
& \min \sum_{t=1}^{T} \sum_{i=1}^{K_{f c s}} X_{i}(t) \frac{P_{f c s}(i)}{\eta_{f c s}(i)} \Delta t \\
& P_{s e}(t)+\sum_{i=1}^{K_{f c s}} X_{i}(t) P_{f c s}(i) \geq P_{r e q}(t) \quad \forall t \in T \\
& \sum_{i=1}^{K_{f c s}} X_{i}(t)=1 \\
& P_{s e}^{\min } \leq P_{s e}(t) \leq P_{s e}^{\max } \\
& S o E^{\min } \leq \operatorname{SoE}(t) \leq S o E^{\max } \quad \forall t \in T \\
& \operatorname{SoE}(t)=\operatorname{SoE}(t-1)-P_{s}(t) \Delta t \quad \forall t \in T \\
& \operatorname{Eloss}_{s e}(t) \leq \alpha_{j} P_{s e}(t)+\beta_{j}+M\left(1-Y_{j}(t)\right) \quad \forall t \in T, \forall j \in J_{\text {se }} \\
& \operatorname{Eloss}_{\text {se }}(t) \geq \alpha_{j} P_{\text {se }}(t)+\beta_{j} \quad \forall t \in T, \forall j \in J_{\text {se }} \\
& \sum_{j=1}^{J_{s e}} Y_{j}(t)=1 \\
& \forall t \in T \\
& P_{s}(t)=P_{s e}(t)+\text { Eloss }_{s e}(t) \\
& \forall t \in T \\
& \operatorname{SoE}(T)=\operatorname{SoE}(0) \\
& X_{i}(t) \in\{0,1\} \\
& \forall t \in T, \forall i \in K_{f c s} \\
& Y_{j}(t) \in\{0,1\}
\end{aligned}
$$

The transition to a linear modelling allows solving the problem efficiently. The discretisation of the FCS energy space and the linearisation of the SE power losses function led us to remove some constraints and introduce others by adding new decision variables. The new model contains $T\left(K_{f c s}+J_{s e}+3\right)$ variables of which $T\left(K_{f c s}+J_{s e}\right)$ binaries. The formulation is therefore noncompact since the number of variables is pseudo-polynomial (which may 
cause a loss of efficiency for large horizons).

\section{Results and simulations}

Branch-and-Cut method refers to a hybrid method of combinatorial optimisation. It is generally employed to solve NP-hard mixed integer linear programming (MILP) problems, such as:

$$
\left\{\begin{array}{l}
\min f(x) \\
g(x) \leq b \\
x \leq x^{\max } \\
x \in \mathbb{Z}^{n}
\end{array}\right.
$$

The Branch-and-Cut method integrates cutting planes to accelerate the optimisation process and Branch-and-Bound methods [21]. The principle is to solve the relaxation of the integer linear problem using the Simplex algorithm, by relaxing the integrity constraints $x \in \mathbb{Z}^{n} \Rightarrow x \in \mathbb{R}^{n}$. If the solution found is feasible for the integer problem, it means that this solution is optimal; otherwise, a cutting plane method is applied in order to reduce the search space by iteratively adding cuts that violate the relaxed solution. This method also allows finding the optimal solution or accelerating the optimisation process of Branch-and-Bound method.

305 The Branch-and-Bound method allows solving an integer linear problem using a tree search. The principle is to separate the relaxed problem into two sub-problems (nodes) according to the fractional solution, which is integer in the master problem, and evaluate their solutions using Simplex algorithm. This process is repeated until the optimal solution is found. 
To solve the combinatorial model, a decision tool is developed in $\mathrm{C}++$ language. This tool uses the Concert application that calls the IBM ILOG CPLEX mathematical optimisation solver ${ }^{3}$. Hydrogen consumption by the fuel cell is summarised in the table below according to the mission profiles, taking into account the optional constraint that recovers the state of energy of the storage element at the end of the mission.

The results of the combinatorial approach are better and less CPU time consuming. With regards to previous results (Table 2), it is clear than for each profile the combinatorial optimization provides a lower consumption (e.g., ESKISEHIR uses DP $=31826 \mathrm{kWs}, \mathrm{QN}=27542 \mathrm{kWs}$, and combinatorial solution with the same constraint at the final state of charge is 27414 $k W s)$. Moreover, even if the final state of charge is not fixed $\mathrm{FL}=29802$ $k W s$ and combinatorial solution is $26924 k W s$. DP and QN solutions are found after few hours instead of only 20 to 40 seconds for the combinatorial problem solving.

Solving the novel combinatorial formulation allows reaching an optimal decision to manage the energy distribution of the HEV sources with a reduced computation time, in comparison with the previously mentioned energy strategies, as shown in Table 2. In order to explain the results obtained using the combinatorial modelling, simulations performed on INRETS and

\footnotetext{
${ }^{3}$ CPLEX uses Branch-and-Cut algorithm to solve integer linear problems. It is applied to reformulate the feasible set of solutions using a pre-processing step and a cutting plane algorithm.
} 
ESKISEHIR mission profiles show that the fuel cell system generally operates in the maximum efficiency range to reduce the consumption of hydrogen, as shown in Figure 5. The displacement of some used set-points obtained with the new proposed combinatorial approach is sufficient to decrease the hydrogen consumption and explain the better results presented in Table 3. This optimal decision corresponds to a lower (or greater) decision at some instant $k \in[1,|T|]$ contributing to a lower overall consumption.

\section{INSERT FIGURE 5 ABOUT HERE}

When the electric motor's power demand is very small, the storage ele-

ment itself provides traction to the vehicle thereby minimising the consumption of hydrogen by the fuel cell. Related to power split shown in Figure 6, as soon as the demand of the electric motor reaches fairly high values, the fuel cell provides more power than the one requested by the electric motor by choosing a maximum operating efficiency point in order to minimise hydrogen consumption; surplus generated power is stored in the storage element for future use. When demand reaches high peaks, the storage element provides part of the power required, while the rest of this power is supplied by the fuel cell using an efficiency operation point that belongs to the interval where the FC is known as efficient.

\section{INSERT FIGURE 6 ABOUT HERE}

In Figure 6, the red curve represents the power of the fuel cell system. The continuous green curve represents the power of the storage element. The blue curve is the sum of the two previous curves and represents the total 
requested charge to deliver. In the figure, each point with an asterisk $(*)$ or when the fuel cell provides more power due to the low demands of the electric motor, and this in order to minimise the consumption of hydrogen 
by choosing an efficient operating point. The decrease in the state of energy

(discharge mode) is recognised when the power required by the motor is high, consecutive to the participation of the storage element for vehicle traction or when demand reaches fairly low thresholds. In this case, the storage element itself provides the power required by the motor.

In addition, at the end of the mission, the final charge state is re-established to the same level as at the beginning of the mission, in consideration of the optional state of energy constraint, as shown in Figure 7. This is reflected in the braking energy recovery before stopping the vehicle in order to reload the storage element, and if the braking energy is insufficient to recover the final state of energy, the FC is enabled for charging.

\section{INSERT FIGURE 7 ABOUT HERE}

To validate the linearisation of the power losses curve, Figure 8 depicts the power losses according to the power supplied or recovered by the storage element. It should be noted that the power losses curve used, defined by the technical specification, matches with the power losses obtained with the proposed modelling using all points on the overall SE plane of the storage element more intensively to obtain the minimum hydrogen consumption.

\section{INSERT FIGURE 8 ABOUT HERE}

In reality, the fuel cell cannot instantaneously deliver high power (e.g., $30 \mathrm{~kW}$ in one second) due to the functioning of its ancillaries. For this reason, a new representative constraint (32) of the fuel cell's dynamic behaviour is introduced, since the instantaneous power supplied between two successive 
moments is limited by a boundary defined by the FC compressor type.

$$
\left|\sum_{i \in K_{f c s}} X_{i}(t+1) P_{f c s}(i)-\sum_{i \in K_{f c s}} X_{i}(t) P_{f c s}(i)\right| \leq P_{f c s}^{l i m} \quad \forall t \in T
$$

which can also be expressed in the following form:

$$
-P_{f c s}^{l i m} \leq \sum_{i \in K_{f c s}} X_{i}(t+1) P_{f c s}(i)-\sum_{i \in K_{f c s}} X_{i}(t) P_{f c s}\left(i \mid \leq P_{f c s}^{l i m} \quad \forall t \in T\right.
$$

The addition of this constraint in the combinatorial model necessarily will impact hydrogen consumption. When the limited power between two successive moments $P_{f c s}^{l i m}$ corresponds to the operating point that has an FCS efficient performance, previously found hydrogen consumption remains optimal. Imposing a low power limitation forces the fuel cell to use a poorer operating point, however, in order to meet the demand of the motor and of the limitation constraint (33), thus leading to overconsumption of hydrogen, as shown in Table 4.

\section{INSERT TABLE 4 ABOUT HERE}

Between two successive moments, the FCS limitation constraint added has small effects, as observed on the HIGHWAY mission profile. This is due to the motor demand, which is relatively constant and does not solicit large power variation. This is also true for the ESKISEHIR mission profile, which is a Tramway profile, in order to not agitate passengers.

It should be noted that, taking into account constraint (33) offers the possibility for fuel cell to charge the supercapacitor in the stopping phases, using an operating point that depends on the fixed power $P_{f c s}^{l i m}$; this may be observed, for example, in Figure 7(b) over the range [820,870]. This choice 
makes it possible to satisfy future demand of the electric motor $P_{r e q}$ when $P_{r e q}>P_{f c s}^{l i m}$. However, this constraint forces the fuel cell to use non-optimal operating points (Figure 9), which leads to a higher hydrogen consumption noted in Table 4.

The combinatorial model was used to achieve optimal power management decisions with a very low computation time compared with the different strategies previously mentioned. In addition, the integration of several optional constraints on fuel cell operations or on the final state of energy of the storage element allows a degree of freedom in the selection of the management strategy.

The performance of the combinatorial model in terms of solution quality and computation time can be exploited to reconfigure the pre-calculated optimal solution whenever the data change on-line due to the disruption of a part of the mission profile. This situation may occur if there is a poor estimate or a detour of the mission profile that the vehicle is to achieve for any reason. In accordance with the decisions already made online by the vehicle, however, the quality of the new adjusted solution depends on the magnitude of these disturbances. Thus, one only has to re-optimise the sequence where the disruption occurs by constraining the final state of energy of the new sequence so that it is the same as the state of energy of the sequence before the reconfiguration process. This condition is used to maintain the validity of the new global sequence. 


\section{Robustness study}

440 Therefore, it is conceivable that the mission profile of the vehicle is obtained from an approximate calculation including some tolerance for error. In this case, it is interesting to carry out a robustness study to provide a correct and optimal solution taking into account the disrupted parameters [22].

The quality of the solutions obtained depends on the reliability of input data. In this section, uncertainties related to the mission profile of the vehicle that may be derived from an estimated calculation are considered. These uncertainties inevitably will impact the validity of the pre-calculated optimal solution found above. To deal with any eventuality that may occur, a robust linear modelling was developed to provide a worst-case robust solution [23], achievable regardless of the degree of disturbance.

In order to circumvent this problem, real-time adjustment and heuristics can be implemented, using the optimal power solution obtained for the storage element $P_{s e}(t), \forall t \in T$, the obtained power provided by the optimisation as reference for a bidirectional converter, and the demand of the electric motor thus ensured by the fuel cell. If at time $t$, engine demand is not perturbed, the power supplied by the fuel cell is the same as that found by the optimisation. If not, power is deduced automatically, $P_{f c s}(t)=P_{r e q}(t)-P_{s e}(t)$. Disruption therefore impacts the estimation of the quantity of hydrogen required to achieve the mission, which causes the vehicle to stop before the end of the mission. Using robust optimisation, however, leads to a better

estimation of the hydrogen quantity required for the worst-case scenario.

Assume that the demand of the electric motor is uncertain and varies in view of the information of its estimated nominal value $P_{r e q}^{n o m}$ and its margin 
of error $P_{r e q}^{e r r}$. However, the actual demand of the electric motor at time $t$ belongs to the interval $\left[P_{r e q}^{n o m}(t)-P_{r e q}^{e r r}(t), P_{r e q}^{\text {nom }}(t)+P_{r e q}^{e r r}(t)\right]$, which can be expressed as:

$$
P_{r e q}(t)=P_{r e q}^{n o m}(t)+\epsilon_{t} P_{r e q}^{e r r}(t) \quad \forall \epsilon_{t} \in[-1,1], t \in T
$$

Taking into account the uncertainties represented in (34) provides optimal worst-case solution using the Soyster's approach [24]. This can be done by replacing the demand satisfaction constraint with the robust constraint (35) in the previous combinatorial model:

$$
P_{s e}(t)+\sum_{i \in K_{f c s}} X_{i}(t) P_{f c s}(i) \geq \max _{-1 \leq \epsilon_{t} \leq 1}\left\{P_{r e q}^{n o m}(t)+\epsilon_{t} P_{r e q}^{e r r}(t)\right\} \quad \forall t \in T
$$

It can be seen that the optimal worst-case solution is reached by fixing uncertainty values to $\epsilon_{t}=1$ when electric motor demand is positive, and to $\epsilon_{t}=-1$ when it is negative. This implies that the mission profile is characterized by high (resp. low) power demands during the traction (resp. braking) phases:

$$
\begin{array}{ll}
P_{s e}(t)+\sum_{i \in K_{f c s}} X_{i}(t) P_{f c s}(i) \geq P_{r e q}^{n o m}(t)+P_{r e q}^{e r r}(t) & \forall t \in T, P_{r e q} \geq 0 \\
P_{s e}(t)+\sum_{i \in K_{f c s}} X_{i}(t) P_{f c s}(i) \geq P_{r e q}^{n o m}(t)-P_{r e q}^{e r r}(t) & \forall t \in T, P_{r e q} \leq 0
\end{array}
$$

Assume now that these uncertainties vary with a rate of $5 \%$, called $\tau=$ 0.05, compared to demand of the electric motor over a given time interval $\left(P_{r e q}^{e r r}(t)=\tau P_{r e q}^{n o m}(t), t \in[200,399 s]\right.$ for the INRETS mission profile, and 465

$t \in[400,799 s]$ for the ESKISEHIR mission profile). The optimal worst-case solution obtained using the robust formulation is expressed in Table 5. 


\section{INSERT TABLE 5 ABOUT HERE}

The worst-case solution obtained is valid regardless of the realisation of scenarios belonging to the set $\left\{\epsilon_{t} \in \mathbb{R} \mid-1 \leq \epsilon_{t} \leq 1, \forall t \in T\right\}$ defined

above. The hydrogen consumption of the robust solution is greater than that calculated using the nominal mission profile. When the perturbation applied the demand of the electric motor is higher than its nominal demand, the fuel cell is prompted to provide more power. Or, in the braking phases, the storage element recovers less power than before, forcing the fuel cell to provide the necessary power in order to avoid violating storage capacity constraints and recovering the final state of energy of the storage element at the end of the mission, if it is taken into account.

\section{Conclusions}

The interest of the approaches outlined in this paper is to manage the power distribution of a hybrid electric vehicle. When the mission profile of the vehicle is known, offline decision strategies are relevant despite their level of criticality for real-time applications. A novel approach has been proposed to improve the quality of decisions for the Energy Management System (EMS), by modelling the energy management problem as a combinatorial optimisation problem after a piecewise linearisation of the curve of the power losses of the storage element (SE) and discretisation of the space of the main energy source (Fuel Cell). This transformation of the problem allowed using exact methods of operations research such as Mixed Integer Linear Programming to solve the problem to optimality, with greatly reduced computation times. Other constraints were introduced and simulated in order to closely 
reproduce the real functioning of the primary source, i.e., power limiting constraints per time step.

To measure the sensitivity of the issue against disturbances related to the demand of the electric motor, a robust study is conducted based on the

495

[1] A. Emadi, S. S. Williamson, Modern automotive power systems: Advancements into the future, in: Power Electronics and Motion Control Conference, 2006. EPE-PEMC 2006. 12th International, IEEE, 2006, pp. 1762-1768. 
515

520

[2] R. van den Hoed, Commitment to fuel cell technology? how to interpret carmakers' efforts in this radical technology, Journal of power sources 141 (2) (2005) 265-271.

[3] J. P. Trovão, P. G. Pereirinha, H. M. Jorge, C. Henggeler Antunes, A multi-level energy management system for multi-source electric vehicles - An integrated rule-based meta-heuristic approach, Applied Energy 105 (2013) 304-318.

[4] T. Sousa, Z. Vale, J. P. Carvalho, T. Pinto, H. Morais, A hybrid simulated annealing approach to handle energy resource management considering an intensive use of electric vehicles, Energy 67 (2014) 81-96.

[5] L. V. Pérez, G. R. Bossio, D. Moitre, G. O. García, Optimization of power management in a hybrid electric vehicle using dynamic programming, Mathematics and Computers in Simulation 73 (1) (2006) 244-254.

[6] M. Guemri, S. Caux, S. U. Ngueveu, F. Messine, Heuristics and lower bound for energy management in hybrid-electric vehicles, in: Proceedings of the 9th International Conference on Modeling, Optimization and Simulation (MOSIM), Bordeaux, 2012.

[7] S. Delprat, T.-M. Guerra, J. Rimaux, Optimal control of a parallel powertrain: from global optimization to real time control strategy, IEEE Transactions on Vehicular Technology 53 (3) (2004) 872-881.

[8] A. Sciarretta, M. Back, L. Guzzella, Optimal control of parallel hybrid electric vehicles, IEEE Transactions on Control Systems Technology 12 (3) (2004) 352-363. 
[9] J. P. Gao, G. M. G. Zhu, E. G. Strangas, F. C. Sun, Equivalent fuel consumption optimal control of a series hybrid electric vehicle, in: Proceedings of the Institution of Mechanical Engineers, Part D: Journal of Automobile Engineering, Vol. 223, Sage Publications, 2009, pp. 10031018.

[10] S. Caux, D. Wanderley-Honda, D. Hissel, M. Fadel, On-line energy management for HEV based on particle swarm optimization, The European Physical Journal Applied Physics (2010) 1-7.

[11] L. Serrao, S. Onori, G. Rizzoni, ECMS as a realization of Pontryagin's minimum principle for HEV control, in: Proceedings of the American Control Conference, IEEE, 2009, pp. 3964-3969.

[12] C. Musardo, G. Rizzoni, Y. Guezennec, B. Staccia, A-ECMS: An adaptive algorithm for hybrid electric vehicle energy management, European Journal of Control 11 (4) (2005) 509-524.

[13] N. J. Schouten, M. A. Salman, N. A. Kheir, Energy management strategies for parallel hybrid vehicles using fuzzy logic, Control Engineering Practice 11 (2) (2003) 171-177.

[14] A. Neffati, M. Guemri, S. Caux, M. Fadel, Energy management strategies for multi source systems, Electric Power Systems Research 102 (2013) 42-49.

[15] S. Caux, W. Hankache, M. Fadel, D. Hissel, On-line fuzzy energy management for hybrid fuel cell systems, International Journal of Hydrogen Energy 35 (5) (2010) 2134-2143. 
[16] H. Khayyam, A. Bab-Hadiashar, Adaptive intelligent energy management system of plug-in hybrid electric vehicle, Energy 69 (2014) 319335.

[17] N. Bizon, M. Radut, M. Oproescu, Energy control strategies for the fuel cell hybrid power source under unknown load profil, Energy 86 (2015) 31-41.

[18] R. K. Ahluwalia, X. Wang, A. Rousseau, R. Kumar, Fuel economy of hydrogen fuel cell vehicles, Journal of Power Sources 130 (1) (2004) $192-201$.

[19] K. T. Chau, C. C. Chan, Emerging energy-efficient technologies for hybrid electric vehicles, Proceedings of the IEEE 95 (4) (2007) 821-835.

[20] R. L. Rardin, Optimization in operations research, Vol. 166, Prentice Hall, New Jersey, 1998.

[21] W. L. Winston, Operations research: applications and algorithms, (third ed.) Duxbury press, Belmont, California, 1994.

[22] D. Bertsimas, D. B. Brown, C. Caramanis, Theory and applications of robust optimization, SIAM Review 53 (3) (2011) 464-501.

[23] A. L. Soyster, Inexact linear programming with generalized resource sets, European Journal of Operational Research 3 (4) (1979) 316-321.

${ }_{580}[24]$ A. L. Soyster, Convex programming with set-inclusive constraints and applications to inexact linear programming, Operations Research 21 (5) (1973) 1154-1157. 


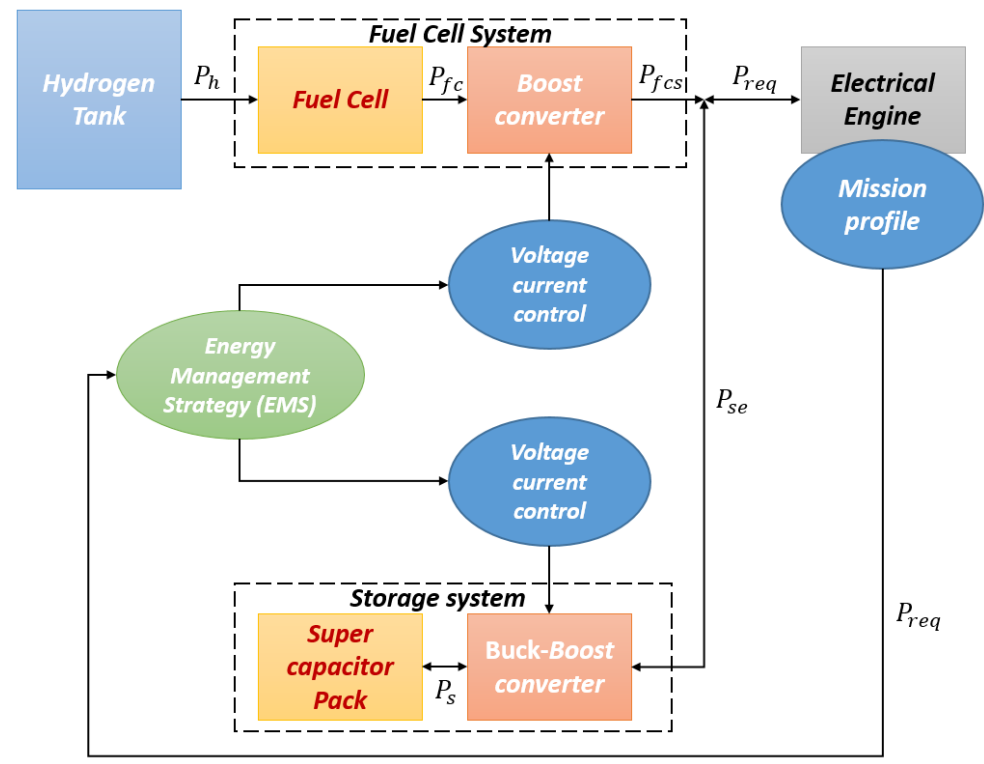

Figure 1: HEV Energy System.

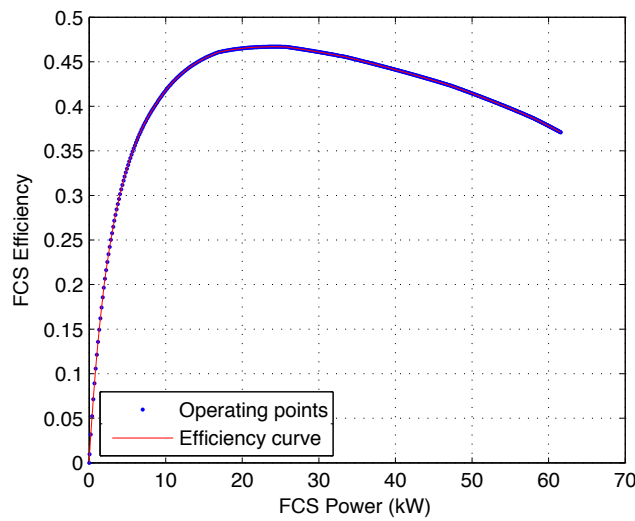

(a) Fuel cell system efficiency.

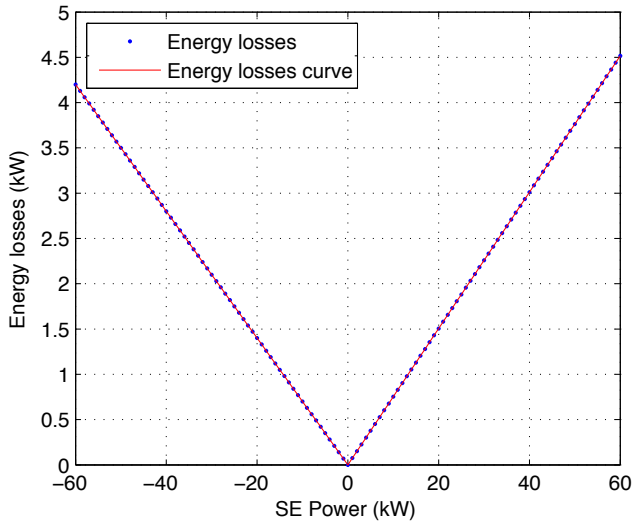

(b) Energy losses of the storage system.

Figure 2: Characteristics of the energy sources. 
Table 1: Input data.

\begin{tabular}{lll}
\hline Notation & Value & Definition \\
\hline$S o E^{\max }$ & $100 \%\left(E_{\text {nom }}=1600 \mathrm{kWs}\right)$ & Maximum energy storable in SE \\
$S o E^{\min }$ & $25 \%(400 \mathrm{kWs})$ & Minimum energy storable in SE \\
$S o E(0)$ & $56.25 \%(900 \mathrm{kWs})$ & Initial energy storable in SE \\
$P_{s e}^{\min }$ & $-60 \mathrm{~kW}$ & Minimum power injected to SE \\
$P_{s e}^{\max }$ & $60 \mathrm{~kW}$ & Maximum power extractable from SE \\
$P_{f c s}^{\max }$ & $70 \mathrm{~kW}$ & Maximum power extractable from FCS \\
$\Delta t$ & $1 s$ & Time stepsize \\
$T$ & & Mission duration \\
\hline
\end{tabular}



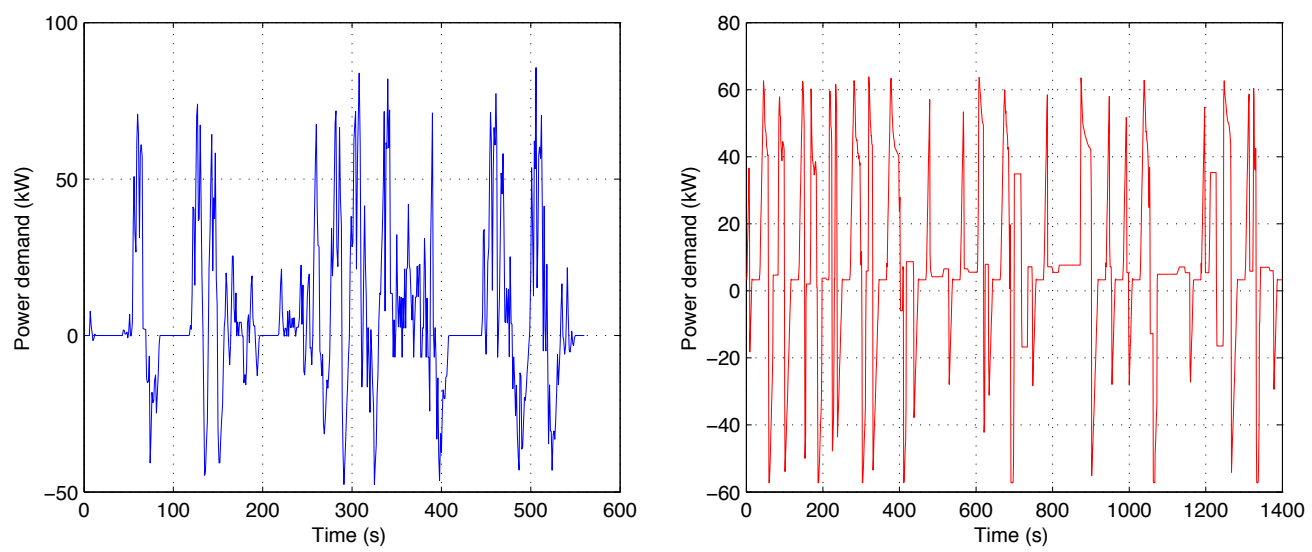

(a) INRETS mission profile over $560 \mathrm{~s}$.

(b) ESKISEHIR mission profile over 1400

$s$.
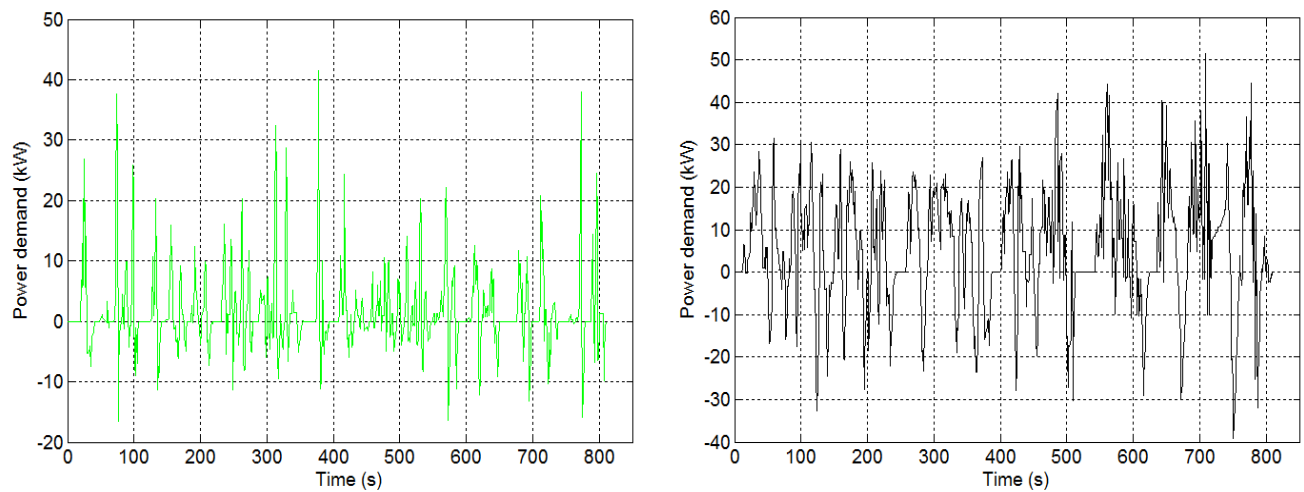

(c) Urban mission profile over $811 \mathrm{~s}$.

(d) Road mission profile over $811 \mathrm{~s}$.

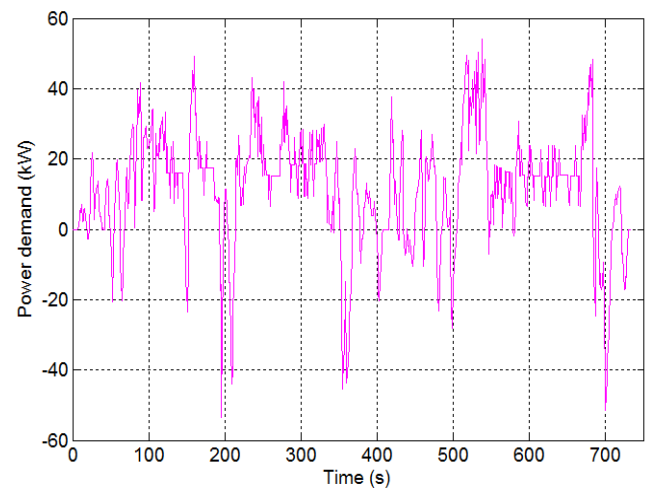

(e) Highway mission profile over $734 s$.

Figure 3: Mission profiles used in the simulation. 


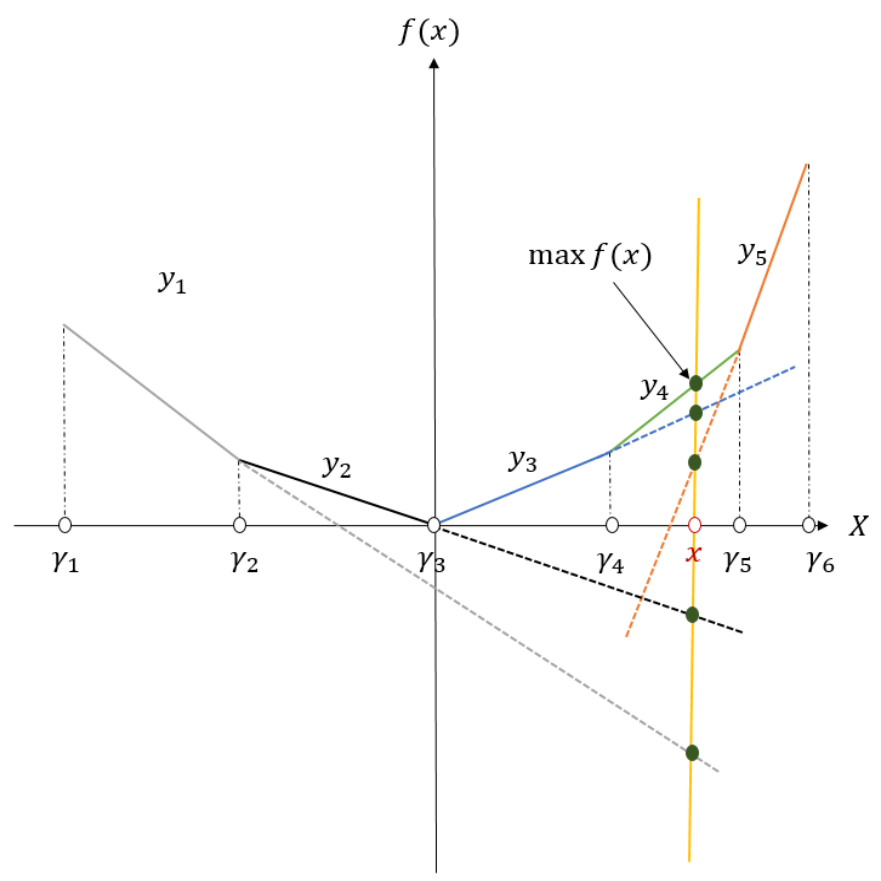

Figure 4: Linearisation of convex function.

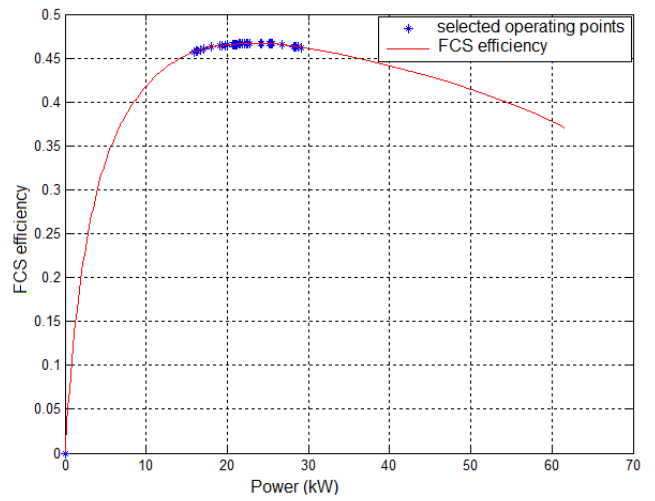

(a) INRETS

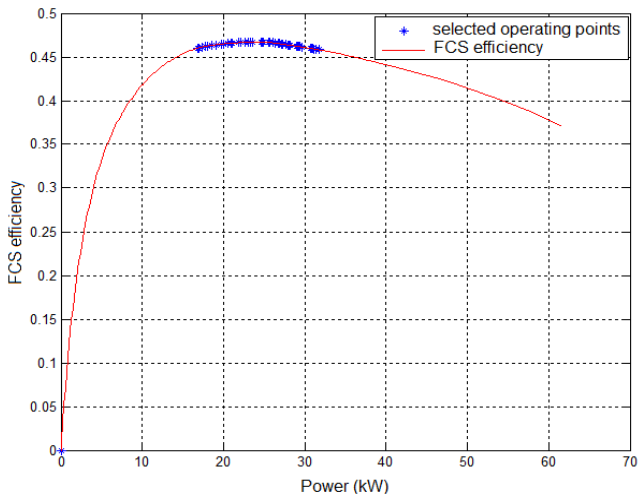

(b) ESKISEHIR

Figure 5: Selected FCS operating points. 


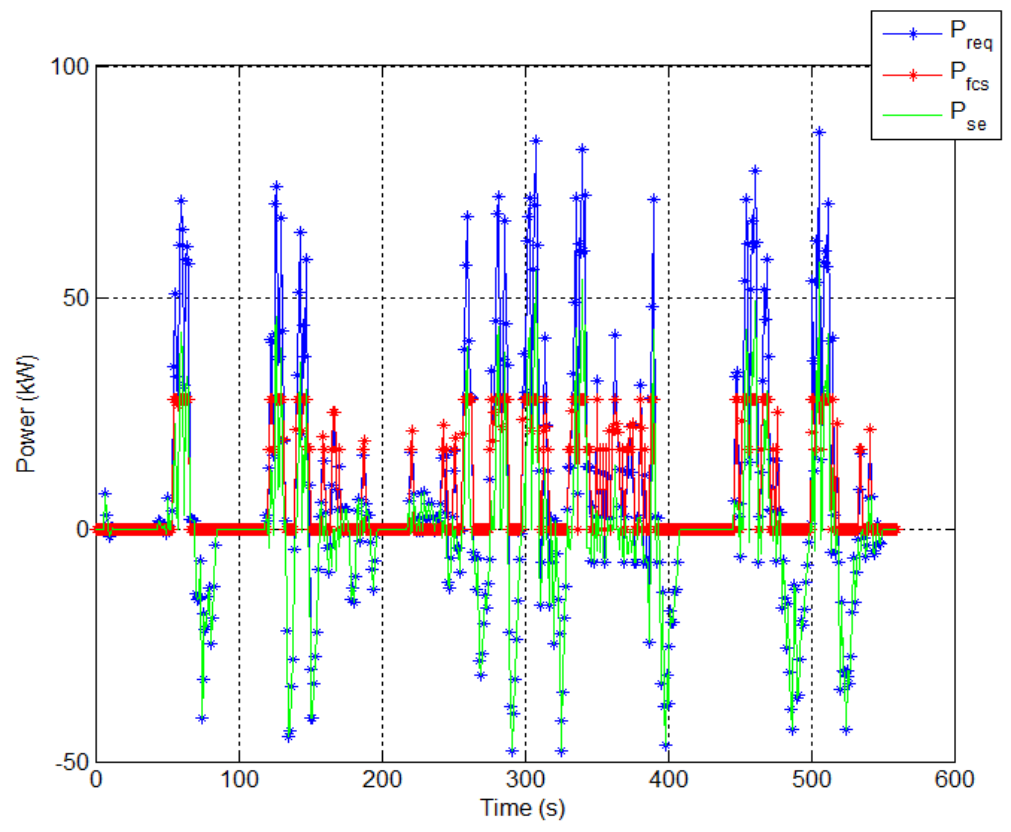

(a) INRETS

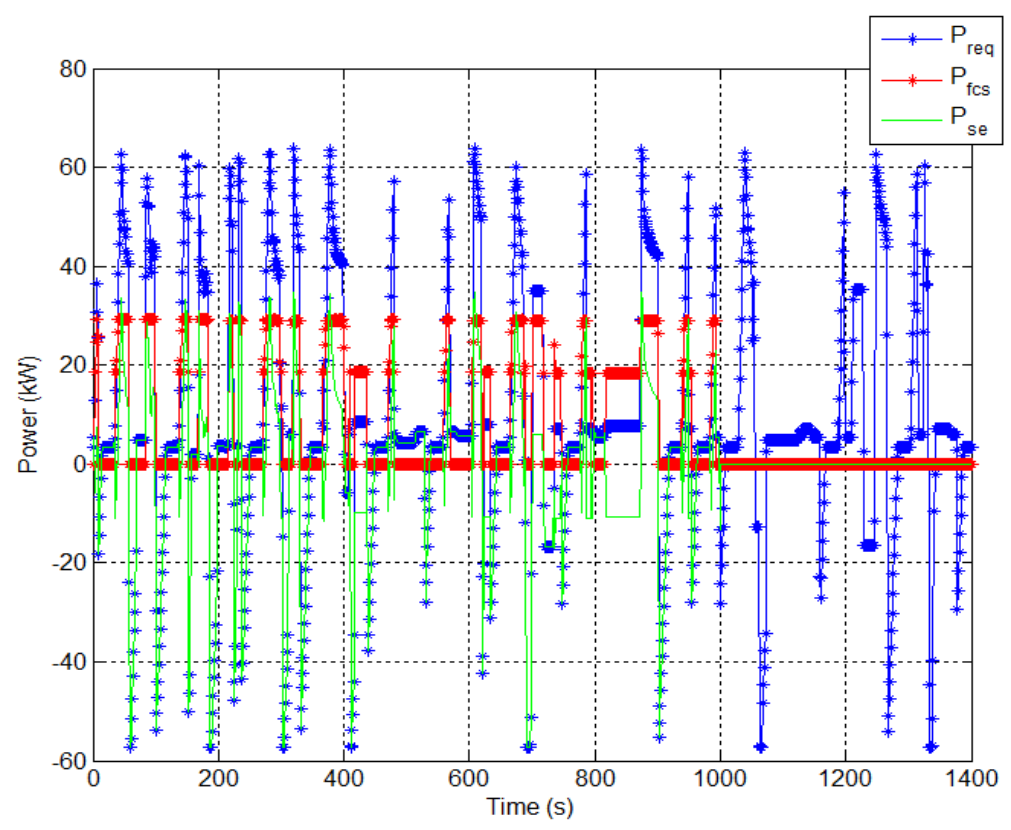

(b) ESKISEHIR

Figure 6: Powers provided by the sources $\left(P_{f c s}, P_{s e}\right)$ and the demand $\left(P_{r e q}\right)$. 


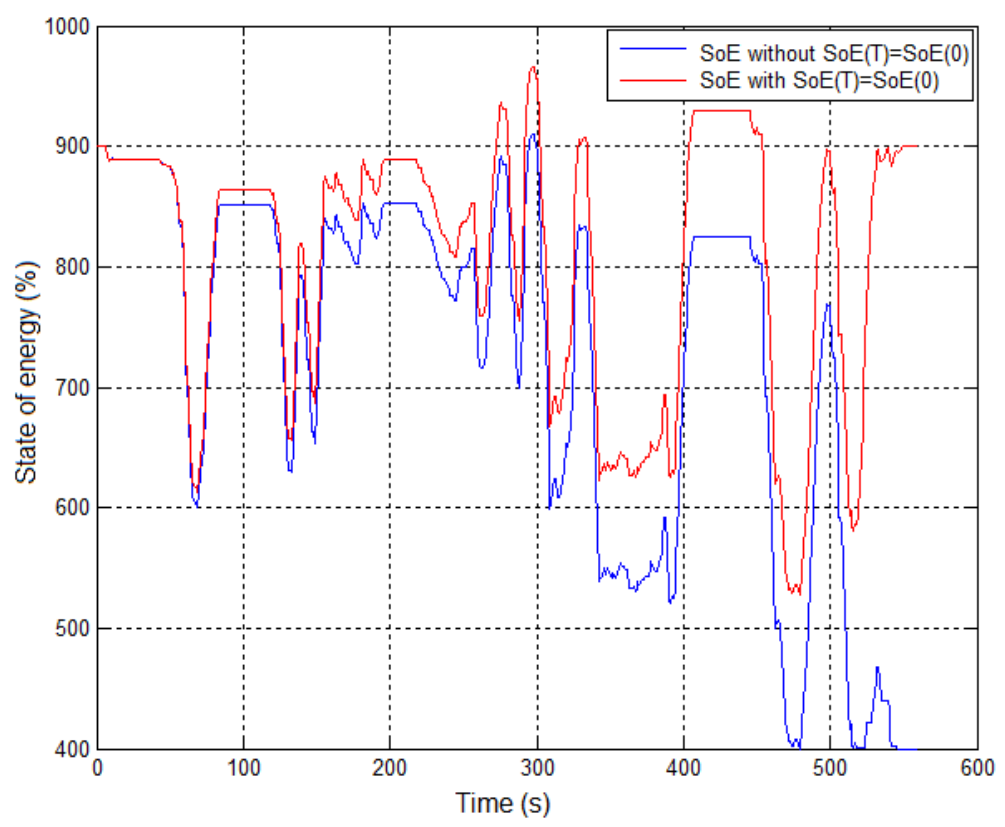

(a) INRETS

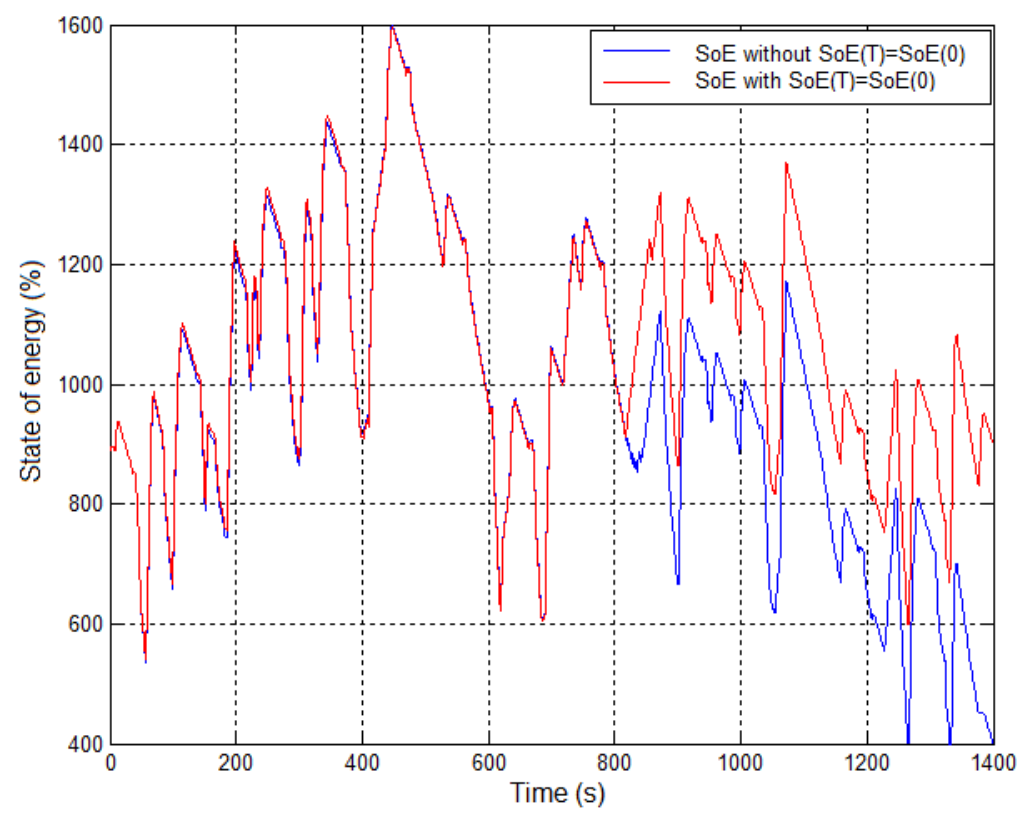

(b) ESKISEHIR

Figure 7: SE available Energy. 


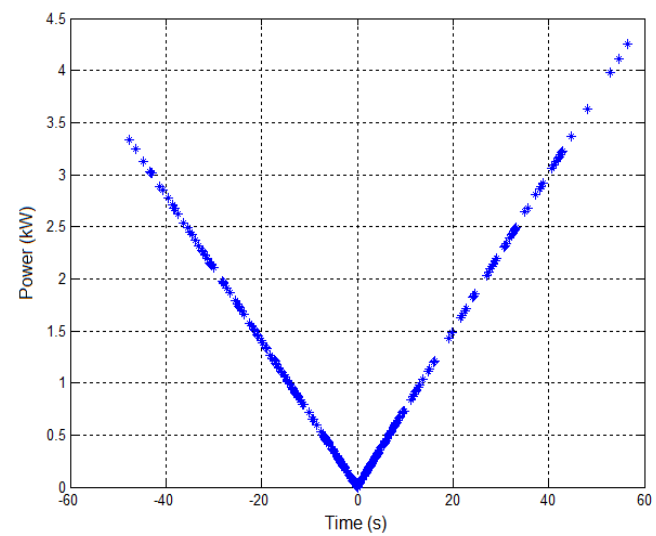

(a) INRETS

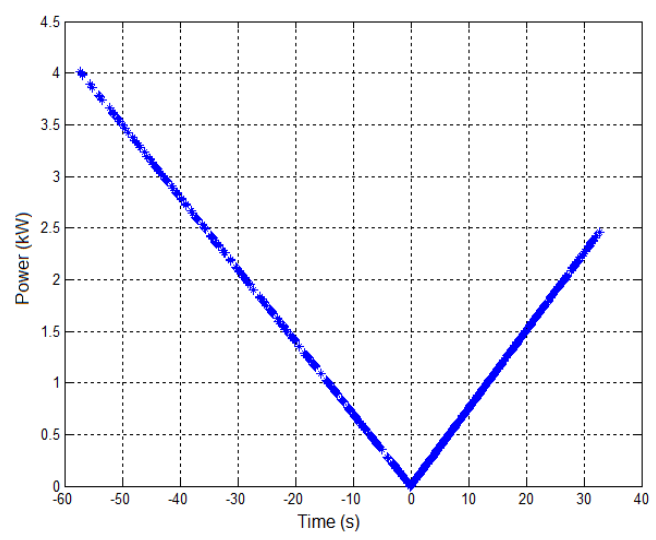

(b) ESKISEHIR

Figure 8: Energy losses by the storage element.

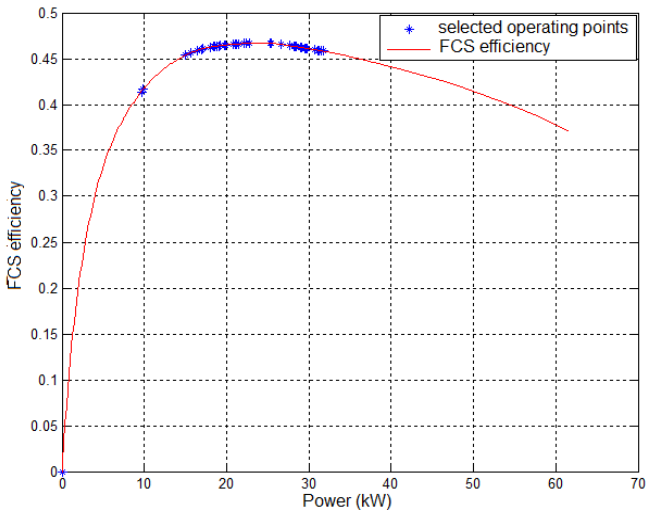

(a) INRETS

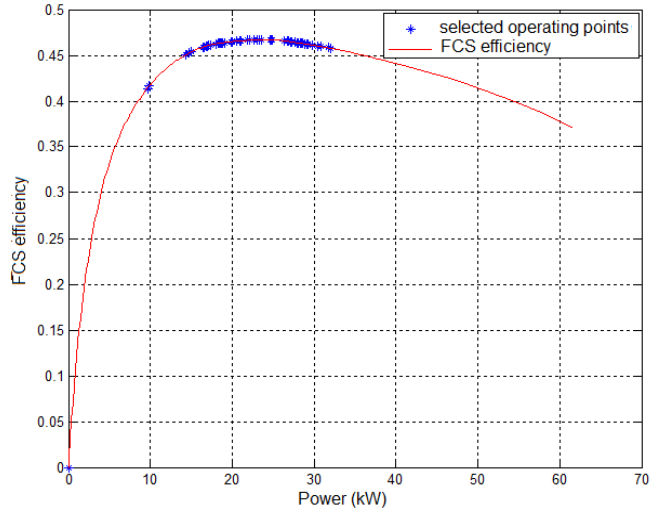

(b) ESKISEHIR

Figure 9: Selected operating points by the fuel cell when the limitation constraint, $P_{f c s}^{l i m}=$ $10 \mathrm{~kW}$, is activated. 
Table 2: Non-linear programming problem solution.

\begin{tabular}{|c|c|c|c|c|}
\hline Mission profile & Approach & $\begin{array}{l}\text { Hydrogen } \\
\text { consump- } \\
\text { tion }\end{array}$ & CPU Time & $\operatorname{SoE}(T)=\operatorname{SoE}(0) ?$ \\
\hline \multirow{3}{*}{ INRETS } & QN & $8750 \mathrm{kWs}$ & $23 m n$ & Yes \\
\hline & FL & $8359 \mathrm{kWs}$ & Real Time & No \\
\hline & DP & $9189.7 \mathrm{kWs}$ & $48 h$ & Yes \\
\hline \multirow{3}{*}{ ESKISEHIR } & QN & $27542 k W s$ & $2.4 h$ & Yes \\
\hline & FL & $29802 k W s$ & Real Time & No \\
\hline & DP & $31826 \mathrm{kWs}$ & $52 h$ & Yes \\
\hline \multirow{3}{*}{ URBAN } & QN & $2954 k W s$ & $78 \mathrm{~min}$ & Yes \\
\hline & FL & $3390.2 \mathrm{kWs}$ & Real Time & No \\
\hline & $\mathrm{DP}$ & $5986 \mathrm{kWs}$ & $44 h$ & Yes \\
\hline \multirow{3}{*}{ ROAD } & QN & $10467 k W s$ & $80 \min$ & Yes \\
\hline & FL & $11031 \mathrm{kWs}$ & Real Time & No \\
\hline & $\mathrm{DP}$ & $12669 \mathrm{kWs}$ & $44 h$ & Yes \\
\hline \multirow{3}{*}{ HIGHWAY } & QN & $19016 \mathrm{kWs}$ & 84 min & Yes \\
\hline & $\mathrm{FL}$ & $19710 \mathrm{kWs}$ & Real Time & No \\
\hline & $\mathrm{DP}$ & $20099 \mathrm{kWs}$ & $48 h$ & Yes \\
\hline
\end{tabular}


Table 3: Results obtained by solving the combinatorial modelling with CPLEX 12.4

\begin{tabular}{cccl}
\hline $\begin{array}{c}\text { Mission } \\
\text { profile }\end{array}$ & $\begin{array}{c}\text { Hydrogen } \\
\text { consumption }\end{array}$ & CPU Time & SoE $(T)=\operatorname{SoE}(0) ?$ \\
\hline \multirow{2}{*}{ INRETS } & $8750 \mathrm{kWs}$ & $3 \mathrm{~s}$ & Yes \\
& $8269 \mathrm{kWs}$ & $5 \mathrm{~s}$ & No \\
\hline \multirow{2}{*}{ ESKISEHIR } & $27514.2 \mathrm{kWs}$ & $26 \mathrm{~s}$ & Yes \\
& $26924 \mathrm{kWs}$ & $45 \mathrm{~s}$ & No \\
\hline URBAN & $2615.95 \mathrm{kWs}$ & $24 \mathrm{~s}$ & Yes \\
& $1598.3 \mathrm{kWs}$ & $67 \mathrm{~s}$ & No \\
\hline ROAD & $9704.42 \mathrm{kWs}$ & $17 \mathrm{~s}$ & Yes \\
& $8892.1 \mathrm{kWs}$ & $23 \mathrm{~s}$ & No \\
\hline HIGHWAY & $18601.4 \mathrm{kWs}$ & $10 \mathrm{~s}$ & Yes \\
& $18333.4 \mathrm{kWs}$ & $11 \mathrm{~s}$ & No \\
\hline
\end{tabular}


Table 4: Results obtained by solving the combinatorial modelling with CPLEX 12.4 in addition of limitation constraint between two successive moments $\Delta t$.

\begin{tabular}{cccl}
\hline $\begin{array}{c}\text { Mission } \\
\text { profile }\end{array}$ & $\begin{array}{c}\text { Hydrogen } \\
\text { consumption }\end{array}$ & CPU time & SoE $(T)=\operatorname{SoE}(0) ?$ \\
\hline \multirow{2}{*}{ INRETS } & $8966.07 \mathrm{kWs}$ & $393 \mathrm{~s}$ & Yes \\
& $8462.37 \mathrm{kWs}$ & $209 \mathrm{~s}$ & No \\
\hline \multirow{2}{*}{ ESKISEHIR } & $27729.7 \mathrm{kWs}$ & $20 \mathrm{~min}$ & Yes \\
& $27112.6 \mathrm{kWs}$ & $15 \mathrm{~min}$ & No \\
\hline \multirow{2}{*}{ URBAN } & $2725.94 \mathrm{kWs}$ & $158 \mathrm{~s}$ & Yes \\
& $1683.69 \mathrm{kWs}$ & $73 \mathrm{~s}$ & No \\
\hline ROAD & $9896.39 \mathrm{kWs}$ & $171 \mathrm{~s}$ & No \\
\hline ROAD & $9074.16 \mathrm{kWs}$ & $554 \mathrm{~s}$ & Yes \\
& $18728.4 \mathrm{kWs}$ & $118 \mathrm{~s}$ & No \\
\hline
\end{tabular}


Table 5: Obtained results with the robust formulation.

\begin{tabular}{cccl}
\hline $\begin{array}{c}\text { Mission } \\
\text { profile }\end{array}$ & $\begin{array}{c}\text { Hydrogen } \\
\text { consumption }\end{array}$ & CPU time & SoE $(T)=\operatorname{SoE}(0) ?$ \\
\hline \multirow{2}{*}{ INRETS } & $9061 \mathrm{kWs}$ & $4 \mathrm{~s}$ & Yes \\
& $8561.33 \mathrm{kWs}$ & $4 \mathrm{~s}$ & No \\
\hline \multirow{2}{*}{ ESKISEHIR } & $28228.1 \mathrm{kWs}$ & $25 \mathrm{~s}$ & Yes \\
& $27639.7 \mathrm{kWs}$ & $24 \mathrm{~s}$ & No \\
\hline
\end{tabular}




\section{Nomenclature}

$\epsilon_{t} \quad$ time-varying uncertainty value (in $\left.[-1,1]\right)$ on the power demand

$\eta_{\text {compressor }}$ air compressor efficiency

$\eta_{c v s} \quad$ buck-boost converter efficiency embedded in the fuel cell stack

$\eta_{f c s} \quad$ Fuel Cell Stack efficiency

$\eta_{f c} \quad$ core hydrogen cell efficiency

$E_{\text {nom }}$ storage capacity of the SE

Eloss $_{s e}$ power losses of the SE (combinatorial approach)

$I_{s c} \quad$ current flowing through the super-capacitors pack

$J_{s e} \quad$ set of linear functions approaching $\mathrm{SE}$ power losses

$K_{f c s} \quad$ set of FCS operating points

Loss $_{\text {cvs }}$ buck-boost SE converter efficiency

$L_{\text {ose }}$ power losses of the SE (non-linear approach)

$M \quad$ big constant

$P_{h} \quad$ equivalent hydrogen power to minimise

$P_{s} \quad$ real power provided or recovered by the SE

$P_{f c s}^{(\max )}$ (maximum) power provided by the FCS

$P_{f c s}^{\text {lim }} \quad$ limited FCS power between two successive moments

Preq demand of the electric motor

$P_{r e q}^{e r r} \quad$ margin of error of the demand of the electric motor

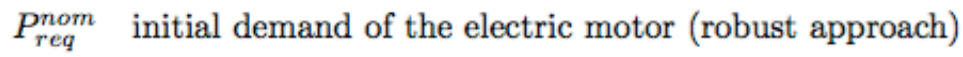

$P_{s e}^{(\min / \max )}$ (minimum/maximum) power provided or recovered by the SE

$R_{s c} \quad$ equivalent resistor of the super-capacitor pack

SoE state of energy of the SE

$T$ mission duration

$t$ time

$X_{i} \quad$ binary variable on the activation of the FCS operating point $i \in K_{f c s}$

$Y_{j} \quad$ binary variable on the activation of the linear function $j \in J_{s e}$ to calculate the power lost

$\left(\alpha_{j}, \beta_{j}\right)$ parameters of line $j$ 